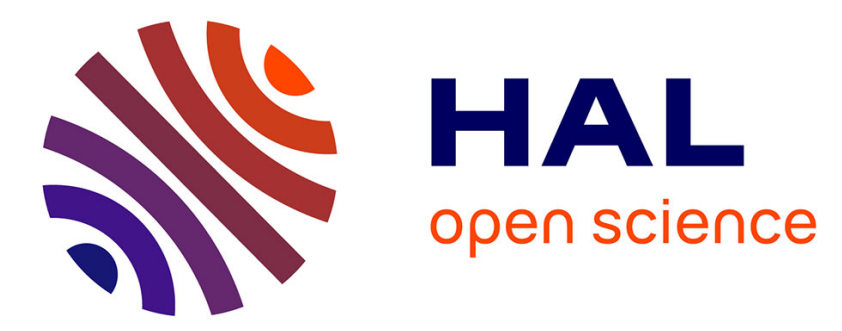

\title{
Analytical Model of Multiple Fault Effect in Three Phases Electrical Systems
}

Claude Delpha, Demba Diallo, Hanane Al Samrout, Nazih Moubayed

\section{To cite this version:}

Claude Delpha, Demba Diallo, Hanane Al Samrout, Nazih Moubayed. Analytical Model of Multiple Fault Effect in Three Phases Electrical Systems. 42nd Annual Conference of the IEEE Industrial Electronics Society (IECON 2016), IEEE, Oct 2016, Florence, Italy. pp.6311 - 6316, 10.1109/IECON.2016.7793728 . hal-01390873

\section{HAL Id: hal-01390873}

https://hal-centralesupelec.archives-ouvertes.fr/hal-01390873

Submitted on 12 Mar 2020

HAL is a multi-disciplinary open access archive for the deposit and dissemination of scientific research documents, whether they are published or not. The documents may come from teaching and research institutions in France or abroad, or from public or private research centers.
L'archive ouverte pluridisciplinaire HAL, est destinée au dépôt et à la diffusion de documents scientifiques de niveau recherche, publiés ou non, émanant des établissements d'enseignement et de recherche français ou étrangers, des laboratoires publics ou privés. 


\title{
Analytical Model of Multiple Fault Effect in Three Phases Electrical Systems
}

\author{
Claude DELPHA*, Demba DIALLO ${ }^{\dagger}$, Hanane Al SAMROUT ${ }^{* \dagger}$ and Nazih MOUBAYED ${ }^{\ddagger}$ \\ *Laboratoire des Signaux et Systèmes (Université Paris Saclay), \\ CNRS, CentraleSupélec, Univ. Paris-Sud, 91192 Gif Sur Yvette, France \\ Email: Claude.Delpha@12s.centralesupelec.fr \\ $\dagger$ Group of Electrical Engineering Paris (Université Paris Saclay), \\ CNRS, CentraleSupélec, Univ. P. et M. Curie, Univ. Paris-Sud, 91192 Gif Sur Yvette, France \\ Demba.Diallo@geeps.centralesupelec.fr \\ $\ddagger$ Scientific Research Center in Engineering (CRSI) \\ Lebanese University, Faculty of Engineering, P.O. Box: 310, Tripoli, Lebanon
}

\begin{abstract}
Due to the increasing requirements of safety and reliability in more electrified applications (transportation for example), fault detection and diagnosis (FDD) of electrical systems has become a hot research topic. In the process of FDD, there are three steps: fault detection, fault isolation and fault estimation. The first two items are the commonly addressed while the last one is less tackled as it requires the development of a fault model which parameters are relevant of the fault. In this paper, we propose an analytical model of multiple fault effects on a three phases electrical system. The model is based on the expressions of the currents in the $(d, q)$ or Park synchronous rotating reference frame. We prove through simulation results the efficiency of the model for fault combination of gain, offset and phase shift. The results show also the accuracy of the model that could be used for fault estimation purpose.
\end{abstract}

\section{INTRODUCTION}

Because of the increasing requirements for safety, reliability and availability in industrial processes and transportation applications, fault detection and diagnosis (FDD) has become a very popular area of research [1], [2].

For FDD process there are different methods that can be used depending on the initial knowledge on the process. There can be mainly classified in three families, model-based [3], language-based and data-driven [4] as displayed in the following Figure 1, [5].

This process requires:

- The modelling of the process,

- The adequate information domain selection (time, frequency, time-frequency or time-scale),

- The relevant features extraction and analysis.

The term fault is commonly used to denote any unexpected behaviour due to the fact that a variable or a parameter is outside its usual range. The symptom is the effect of the fault, that can be observed or estimated.

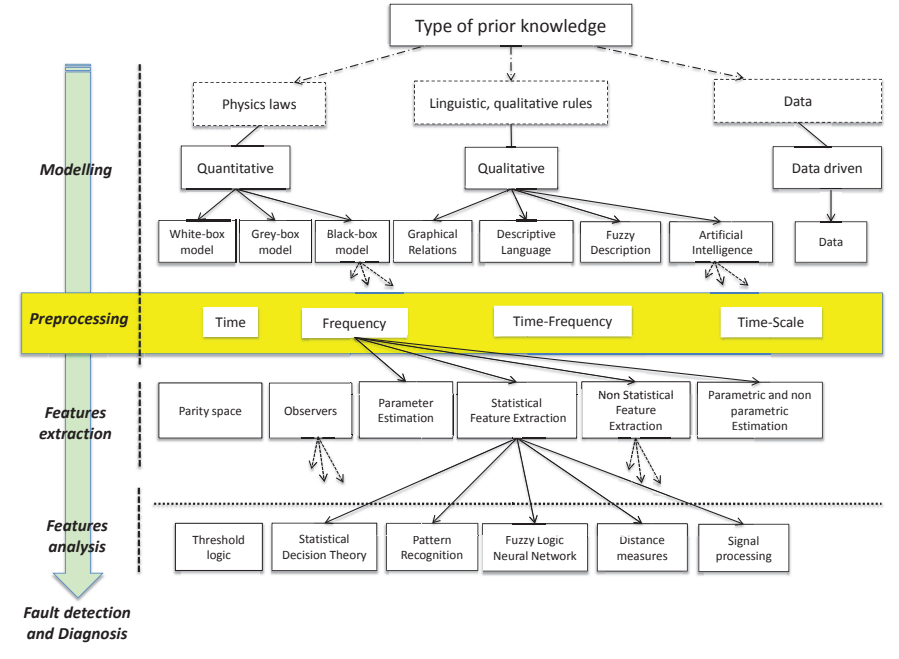

Figure 1. Fault detection and diagnosis approaches

The FDD process includes three steps, fault detection, fault isolation and fault estimation. In fact, to extract the characteristics of the fault (fault estimation), a fault model must be derived which parameters reflect as accurately as possible the fault. The method is summarized in Figure 2.

In this work we propose to focus on the fault modelling in a three phase system. With a sufficiently accurate model, the fault estimation could be easily considered while inverting the model for example in diagnosis or prognosis purposes.

For three phases AC drives, the most common features used for fault detection and diagnosis [6] in the literature are:

- the currents as they are usually available to the control, [7], [8]

- the other electromagnetic quantities [9], [10] such as 


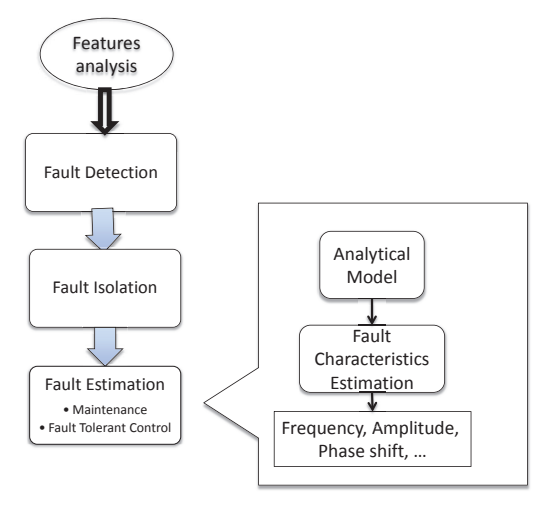

Figure 2. FDD procedure

power, torque, fluxes, etc...

- the vibrations signals [11], [12].

There are three types of fault occurrence: the abrupt fault, the gradual fault and the intermittent fault. Their description are displayed in Figure 3.

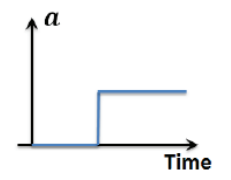

Abrupt

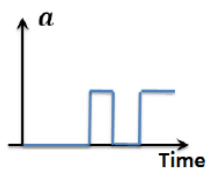

Intermittent

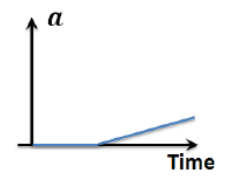

Gradual
Figure 3. Main fault types

For each fault type an analytical model should be derived for the fault estimation. In this work, we are mainly interested in faults occurred in an three phase electrical system. The features under interest are the currents flowing into the system. The paper contribution is the development of an analytical model of the combined faults based on the currents in the $(\mathrm{d}, \mathrm{q})$ synchronous rotating frame. The paper organization is a follows:

- section II presents the general fault model for a three phase system,

- section III presents the model in the case of an AC drive structure. The machine windings coupling (star or delta) is considered,

- the model is validated in section IV,

- a conclusion closes the paper.

In order to study the influence of a fault on each of park currents, it is necessary to develop a model describing the variation of these currents in case of presence of a certain symptom (gain variation, offset, phase shift, or the combination of two or three symptoms). In this chapter, we'll derive this model and evaluate its validity it in a noisy environment.

The objective is to find an analytical model that could fit with the data measured on a real process.

\section{FAULT EFFECT MODELLING}

\section{A. Current modelling}

Considering that faults in a three phase electrical system is performed on its feeding currents, we propose here to consider the combined effect of the faults on these currents. Let's consider the 3 currents $i_{a}, i_{b}, i_{c}$ respectively for the 3 phases $a, b, c$. With a healthy behavior, these currents can be written $i_{a_{h}}, i_{b_{h}}, i_{c_{h}}$ such as :

$$
\begin{aligned}
& i_{a_{h}}=I \sqrt{2} \sin (\theta) \\
& i_{b_{h}}=I \sqrt{2} \sin \left(\theta-\frac{2 \pi}{3}\right) \\
& i_{c_{h}}=I \sqrt{2} \sin \left(\theta+\frac{2 \pi}{3}\right)
\end{aligned}
$$

Where: $\theta=\omega t$ with $\omega$ the frequency and $t$ the time variable. $I$ is the current root mean square value.

We propose here to consider a combination of several basic faults (gain, phase, offset, ...). For this work, we consider that when a fault occur, the current signal elements in the three phases $a, b, c$ of the electrical system are modified in terms of amplitude (gain fault $\Delta_{i_{j}}$ ), mean (offset fault $\gamma_{j}$ ) and time delay (phase shifting fault $\varphi_{j}$ ) in the $j t h$ corresponding phase of the motor. We can then write the faulty signals $i_{a_{f}}, i_{b_{f}}$, $i_{c_{f}}$ such as :

$$
\begin{gathered}
i_{a_{f}}=\left(I \sqrt{2}+\Delta_{i_{1}}\right) \sin \left(\theta+\varphi_{1}\right)+\gamma_{1} \\
i_{b_{f}}=\left(I \sqrt{2}+\Delta_{i_{2}}\right) \sin \left(\theta-\frac{2 \pi}{3}+\varphi_{2}\right)+\gamma_{2} \\
i_{c_{f}}=\left(I \sqrt{2}+\Delta_{i_{3}}\right) \sin \left(\theta+\frac{2 \pi}{3}+\varphi_{3}\right)+\gamma_{3}
\end{gathered}
$$

Then while we consider the evolution of the currents in the Park transform domain, we obtain the two currents $i_{d}$ and $i_{q}$ and the homopolar component $i_{0}$ from the three currents $i_{a}$, $i_{b}, i_{c}$ such as :

$$
\begin{gathered}
i_{d}=\frac{2}{3}\left[i_{a} \cos (\theta)+i_{b} \cos \left(\theta-\frac{2 \pi}{3}\right)+i_{c} \cos \left(\theta+\frac{2 \pi}{3}\right)\right] \\
i_{q}=\frac{2}{3}\left[i_{a} \sin (\theta)+i_{b} \sin \left(\theta-\frac{2 \pi}{3}\right)+i_{c} \sin \left(\theta+\frac{2 \pi}{3}\right)\right] \\
i_{0}=\frac{1}{3}\left[i_{a}+i_{b}+i_{c}\right]
\end{gathered}
$$

Then, if we compute the equations $i_{d}, i_{q}$ and $i_{0}$ in the faulty case while considering (4), (5), (6), we obtain the faulty expressions $i_{d_{f}}, i_{q_{f}}$ and $i_{0_{f}}$.

\section{B. Fault effect in the Park transform}

1) Faulty signal calculation of: $i_{d_{f}}$

Equation (7) can be written as the following one :

$i_{d_{f}}=\frac{2}{3}\left[i_{a_{f}} \cos (\theta)+i_{b_{f}} \cos \left(\theta-\frac{2 \pi}{3}\right)+i_{c_{f}} \cos \left(\theta+\frac{2 \pi}{3}\right)\right]$ 
Let's denote the different constants due to the three considered fault effects for the $d$ component such as :

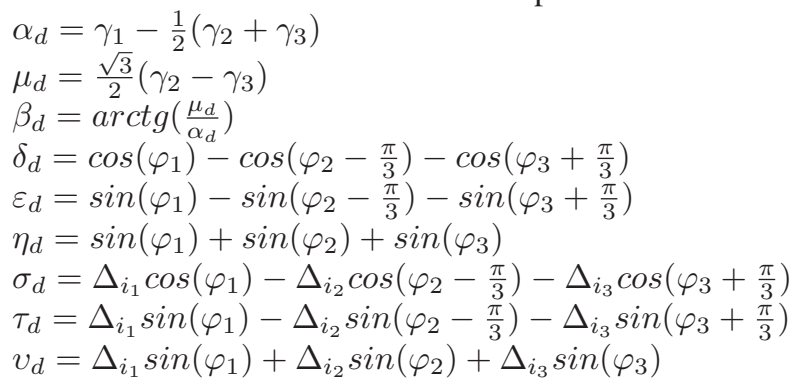

Thus, we can obtain the expression of the faulty current along with the $d$ component of the park transform as:

$$
\begin{gathered}
i_{d_{f}}=\frac{2}{3}\left[\sqrt{\alpha_{d}^{2}+\mu_{d}^{2}} \cos \left(\theta-\beta_{d}\right)+\right. \\
I \sqrt{2}\left(\frac{1}{2} \sqrt{\delta_{d}^{2}+\varepsilon_{d}^{2}} \cos \left(2 \theta-\operatorname{arctg}\left(\frac{\delta_{d}}{\varepsilon_{d}}\right)\right)+\frac{1}{2} \eta_{d}\right)+ \\
\left.\frac{1}{2} \sqrt{\sigma_{d}^{2}+\tau_{d}^{2}} \cos \left(2 \theta-\operatorname{arctg}\left(\frac{\sigma_{d}}{\tau_{d}}\right)\right)+\frac{1}{2} v_{d}\right]
\end{gathered}
$$

Nota : The $\operatorname{arctg}($.$) function derives an angle with an$ accuracy $\pm k \pi$ with $\mathrm{k}$ an integer value.

\section{2) Faulty signal calculation of: $i_{q_{f}}$}

Equation (8) can be written as the following one :

$$
i_{q_{f}}=\frac{2}{3}\left[i_{a_{f}} \sin (\theta)+i_{b_{f}} \sin \left(\theta-\frac{2 \pi}{3}\right)+i_{c_{f}} \sin \left(\theta+\frac{2 \pi}{3}\right)\right]
$$

Let's denote the different constants due to the three considered fault effects for the $q$ component such as :

$$
\begin{aligned}
& \alpha_{q}=\gamma_{1}-\frac{1}{2}\left(\gamma_{2}+\gamma_{3}\right) \\
& \mu_{q}=\frac{\sqrt{3}}{2}\left(\gamma_{3}-\gamma_{2}\right) \\
& \beta_{q}=\operatorname{arctg}\left(\frac{\alpha_{q}}{\mu_{q}}\right) \\
& \delta_{q}=\sin \left(\varphi_{1}\right)-\sin \left(\varphi_{2}-\frac{\pi}{3}\right)-\sin \left(\varphi_{3}+\frac{\pi}{3}\right) \\
& \varepsilon_{q}=-\left[\cos \left(\varphi_{1}\right)-\cos \left(\varphi_{2}-\frac{\pi}{3}\right)-\cos \left(\varphi_{3}+\frac{\pi}{3}\right)\right] \\
& \eta_{q}=\cos \left(\varphi_{1}\right)+\cos \left(\varphi_{2}\right)+\cos \left(\varphi_{3}\right) \\
& \sigma_{q}=\Delta_{i_{1}} \sin \left(\varphi_{1}\right)-\Delta_{i_{2}} \sin \left(\varphi_{2}-\frac{\pi}{3}\right)-\Delta_{i_{3}} \sin \left(\varphi_{3}+\frac{\pi}{3}\right) \\
& \tau_{q}=-\left[\Delta_{i_{1}} \cos \left(\varphi_{1}\right)-\Delta_{i_{2}} \cos \left(\varphi_{2}-\frac{\pi}{3}\right)-\Delta_{i_{3}} \cos \left(\varphi_{3}+\frac{\pi}{3}\right)\right] \\
& v_{q}=\Delta_{i_{1}} \cos \left(\varphi_{1}\right)+\Delta_{i_{2}} \cos \left(\varphi_{2}\right)+\Delta_{i_{3}} \cos \left(\varphi_{3}\right)
\end{aligned}
$$

We can notice that : $\alpha_{q}=\alpha_{d} ; \mu_{q}=-\mu_{d} ; \delta_{q}=\varepsilon_{d}$; $\varepsilon_{q}=-\delta_{d} ; \sigma_{q}=\tau_{d} ; \tau_{q}=-\sigma_{d}$.

$$
\begin{aligned}
i_{q f}=\frac{2}{3}\left[\sqrt{\alpha_{q}^{2}+\mu_{q}^{2}} \cos \left(\theta-\beta_{q}\right)+\right. \\
I \sqrt{2}\left(\frac{1}{2} \sqrt{\delta_{q}^{2}+\varepsilon_{q}^{2}} \cos \left(2 \theta-\operatorname{arctg}\left(\frac{\delta_{q}}{\varepsilon_{q}}\right)\right)+\frac{1}{2} \eta_{q}\right)+ \\
\left.\frac{1}{2} \sqrt{\sigma_{q}^{2}+\tau_{q}^{2}} \cos \left(2 \theta-\operatorname{arctg}\left(\frac{\sigma_{q}}{\tau_{q}}\right)\right)+\frac{1}{2} v_{q}\right]
\end{aligned}
$$

3) Faulty signal calculation of : $i_{0_{f}}$
Equation (9) can be written as the following one :

$$
\begin{gathered}
i_{0_{f}}=\frac{1}{3}\left[\gamma_{1}+\gamma_{2}+\gamma_{3}+\left(I \sqrt{2}+\Delta_{i_{1}}\right) \cos \left(\varphi_{1}\right) \sin (\theta)\right. \\
-\left(I \sqrt{2}+\Delta_{i_{2}}\right) \cos \left(\varphi_{2}+\frac{\pi}{3}\right) \sin (\theta) \\
-\left(I \sqrt{2}+\Delta_{i 3}\right) \cos \left(\varphi_{3}-\frac{\pi}{3}\right) \sin (\theta) \\
+\left(I \sqrt{2}+\Delta_{i_{1}}\right) \sin \left(\varphi_{1}\right) \cos (\theta) \\
-\left(I \sqrt{2}+\Delta_{i_{2}}\right) \sin \left(\varphi_{2}+\frac{\pi}{3}\right) \cos (\theta) \\
\left.-\left(I \sqrt{2}+\Delta_{i_{3}}\right) \sin \left(\varphi_{3}-\frac{\pi}{3}\right) \cos (\theta)\right]
\end{gathered}
$$

\section{APPLICATION TO PARTICULAR MACHINE COUPLING}

As an example, for the fault detection and diagnosis of an induction motor drive, the output currents of the inverter feeding the AC drive can be considered. (Figure 4). Nevertheless, the coupling mode of the electrical machine have to be considered as a particular way of use.

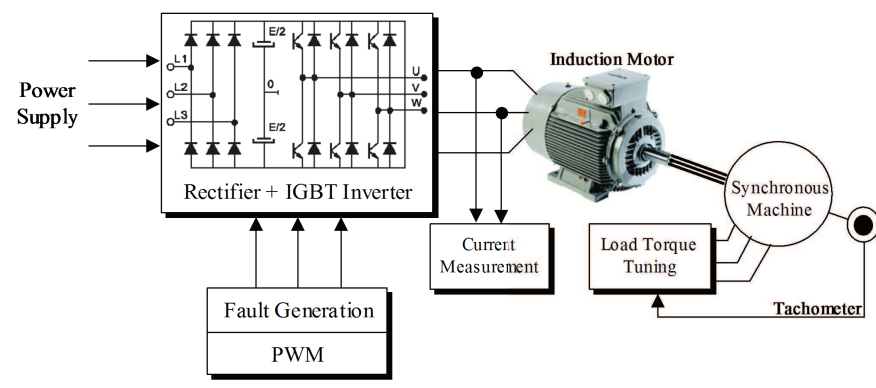

Figure 4. Voltage fed induction motor

According to the machine coupling mode, specific conditions can be deduced from the Park's transform currents given in equations (11), (13), (14). For our study, we have considered 3 different coupling modes :

- Star coupling with an isolated neutral

- Star coupling with a non isolated neutral

- Delta coupling

This allows us to more easily explain and interpret the results obtained after a fault occurrence.

\section{A. Star connection coupling with a non isolated neutral}

With a star connection with non isolated neutral, there are no constraint on the currents. In this case, the equations in the faulty cases are not constrained. Thus the representations of this currents in the Park transform domain cannot be reduced.

\section{B. Star connection coupling with an isolated neutral}

While using a star connection coupling with an isolated neutral, the currents feeding the machine are constrained (see Figure 5).

In this case, the sum of the currents feeding the three phases of the electrical system and arriving in the same neutral node 


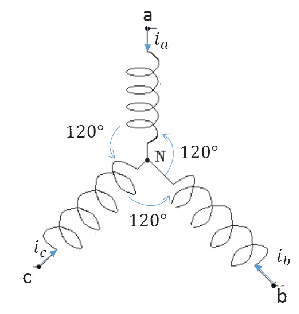

Figure 5. Star coupling with isolated neutral mode

must be zero either for healthy and faulty behaviors. So in the faulty case, we have to respect the condition $\sum i_{j_{f}}=$ 0 . Then whatever the fault (gain, offset and phase shifting) combination, we have to respect the equation $i_{a_{f}}+i_{b_{f}}+i_{c_{f}}=$ 0 . Therefore, we have:

$$
\begin{aligned}
\gamma_{1} & =-\left(\gamma_{2}+\gamma_{3}\right) \\
\varphi_{1} & =\frac{\varphi_{2}+\varphi_{3}}{2} \pm k \pi \quad k=1,2, \ldots \\
\Delta_{i_{1}} & =-2 \Delta_{i_{2}} \cos \left(\frac{\varphi_{2}}{2}-\frac{\varphi_{3}}{2}-\frac{2 \pi}{3}\right) \\
\Delta_{i_{2}} & =\Delta_{i_{3}}
\end{aligned}
$$

So if we consider no phase shifting on the current in phase $\mathrm{b}$ and $\mathrm{c}$, i.e $\varphi_{2}=\varphi_{3}=0$ this induces that there will have no phase shifting on phase a $\varphi_{1}=0$ then we will have constraints on the gain faults such as :

$$
\begin{aligned}
\Delta_{i_{1}} & =-2 \Delta_{i_{2}} \cos \left(-\frac{2 \pi}{3}\right) \\
& =\Delta_{i_{2}}=\Delta_{i_{3}}
\end{aligned}
$$

So, while there is no phase shifting, the gain fault effect will be the same for the three phases of the induction machine.

\section{Delta connection coupling}

For a delta connection coupling mode, the currents circulation can be modeled by the scheme depicted in Figure 6 . In

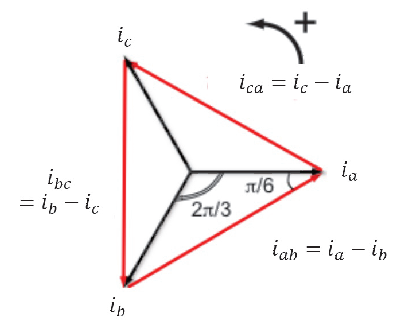

Figure 6. Fresnel representation of currents

such mode, the currents to be considered are those in the delta triangle scheme i.e in the branches $a b, b c$ and $c a$ leading to the corresponding currents $i_{a b}, i_{b c}$, and $i_{c a}$. It is well known that they can be written as denoted in equation (17):

$$
\begin{aligned}
i_{a b} & =i_{a}-i_{b} \\
i_{b c} & =i_{b}-i_{c} \\
i_{c a} & =i_{c}-i_{a}
\end{aligned}
$$

In the heathy or faulty case these equations will be respectively written with a $h$ or $f$ letter as lowerscript. Then in a balanced system, the corresponding currents will be:

$$
\begin{aligned}
i_{a b_{h}} & =I \sqrt{\frac{2}{3}} \sin \left(\theta+\frac{\pi}{6}\right) \\
i_{b c_{h}} & =I \sqrt{\frac{2}{3}} \sin \left(\theta-\frac{\pi}{2}\right) \\
i_{c a_{h}} & =I \sqrt{\frac{2}{3}} \sin \left(\theta-\frac{7 \pi}{6}\right)
\end{aligned}
$$

If we consider that $\Delta_{i_{z n}}, \gamma_{z n}$ and $\varphi_{z n}$ are respectively the gain, offset and phase shifting equivalent faults in the delta mode coupling for the currents in the $z n^{t h}$ branch, we can then write them according to the faults of the three original currents :

So, let:

$$
\begin{array}{rlr}
\Delta_{i_{1}} & =I \sqrt{2}\left(\frac{1}{\sqrt{3}}-1\right)+\Delta_{i_{12}} & \\
\Delta_{i_{2}} & =I \sqrt{2}\left(\frac{1}{\sqrt{3}}-1\right)+\Delta_{i_{23}} & \\
\Delta_{i_{3}}=I \sqrt{2}\left(\frac{1}{\sqrt{3}}-1\right)+\Delta_{i_{31}} & \\
\gamma_{1}=\gamma_{12} & \gamma_{2}=\gamma_{23} & \gamma_{3}=\gamma_{31} \\
\varphi_{1}=\frac{\pi}{6}+\varphi_{12} & \varphi_{2}=\frac{\pi}{6}+\varphi_{23} & \varphi_{3}=\frac{\pi}{6}+\varphi_{31}
\end{array}
$$

Then we obtain the faulty currents in the equivalent delta coupling mode as :

$$
\begin{aligned}
i_{a b_{f}} & =\left(I \sqrt{2}+\Delta_{i_{1}}\right) \sin \left(\theta+\varphi_{1}\right)+\gamma_{1} \\
i_{b c_{f}} & =\left(I \sqrt{2}+\Delta_{i_{2}}\right) \sin \left(\theta-\frac{2 \pi}{3}+\varphi_{2}\right)+\gamma_{2} \\
i_{c a_{f}} & =\left(I \sqrt{2}+\Delta_{i_{3}}\right) \sin \left(\theta-\frac{4 \pi}{3}+\varphi_{3}\right)+\gamma_{3}
\end{aligned}
$$

For the delta coupling mode the currents must respect the constraint $i_{a b}+i_{b c}+i_{c a}=0$

Under this constraints, for the faulty currents, we show that the faults will satisfy the following relations :

$$
\begin{gathered}
\gamma_{12}=-\left(\gamma_{23}+\gamma_{31}\right) \\
\varphi_{12}=\frac{\varphi_{23}+\varphi_{31}}{2} \pm k \pi \quad k=1,2, \ldots \\
\Delta_{i_{12}}=-I \sqrt{2}\left(\frac{1}{\sqrt{3}}-1\right)- \\
2 \Delta_{i_{31}} \cos \left(\frac{\varphi_{23}}{2}-\frac{\varphi_{31}}{2}-\frac{2 \pi}{3}\right)- \\
2 I \sqrt{2}\left(\frac{1}{\sqrt{3}}-1\right) \cos \left(\frac{\varphi_{23}}{2}-\frac{\varphi_{31}}{2}-\frac{2 \pi}{3}\right)
\end{gathered}
$$

Considering these results, the delta connection is a particular case of the star connection coupling mode and then the same results are obtained. 


\section{Model VAlidation}

In order to validate the derived analytical model, we propose to consider three phases currents $i_{a}, i_{b}, i_{c}$ and corrupt them with the mentioned faults. The park transform is applied to the faulty signals and the resulting waveforms obtained for the currents $i_{d}, i_{q}$ and $i_{0}$ are compared to the ones proposed in the modelling and obtained through the equations (11), (13), and (14).

For the validation we propose to consider a star connection coupling with isolated neutral. At the first step, we create three phase currents $i_{a}, i_{b}, i_{c}$ where the signal frequency is $50 \mathrm{~Hz}$, the signal to noise ratio is $20 \mathrm{~dB}$, the currents amplitude peak to peak is 2A (Figure 7).

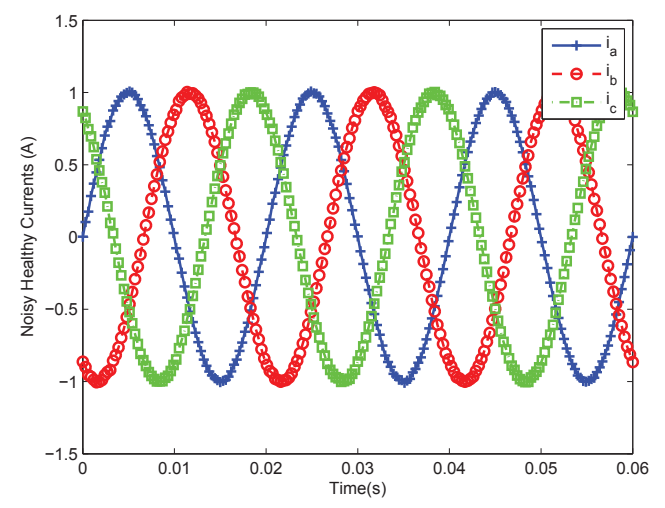

Figure 7. Healthy currents with $\mathrm{SNR}=20 \mathrm{~dB}$

In these conditions, the Park transformed currents $i_{d}, i_{q}$ and $i_{0}$ are DC values.

Then we corrupt the currents with the mentioned faults simultaneously. For the displayed results we will consider a fault on the phase a i.e on $i_{a}$ with a gain fault of $25 \%$ of the original current amplitude, an offset fault with an amplitude of $15 \%$ of the original current amplitude and a phase shift of $35 \%$ of the full phase range. The effect of these faults combination is given in Figure 8.

With the faults combination, the Park transformed is computed. The results highlights sinusoidal waveforms for the currents $i_{d_{f}}$, and $i_{q_{f}}$ with varying amplitude. The spectrum analysis of these signals highlights that the main frequency for both is $100 \mathrm{~Hz}$ (twice the original frequency). The current $i_{0_{f}}$ has a noisy resultant signal with zero mean (Figure 9) and a lower amplitude. With a spectrum analysis we can confirm that the main frequency of this signal is $50 \mathrm{~Hz}$ (same frequency as the original three phase currents).

For the same fault combination, we have computed the model derived in the equations (11), (13), and (14) respectively corresponding to the Park currents $i_{d_{f}}, i_{q_{f}}$ and $i_{0_{f}}$. The result obtained for the modelled currents are displayed in Figure 10.

To check the efficiency of the model and compare its results with those obtained while computing directly the Park transformation, we have plotted on the same figure the same

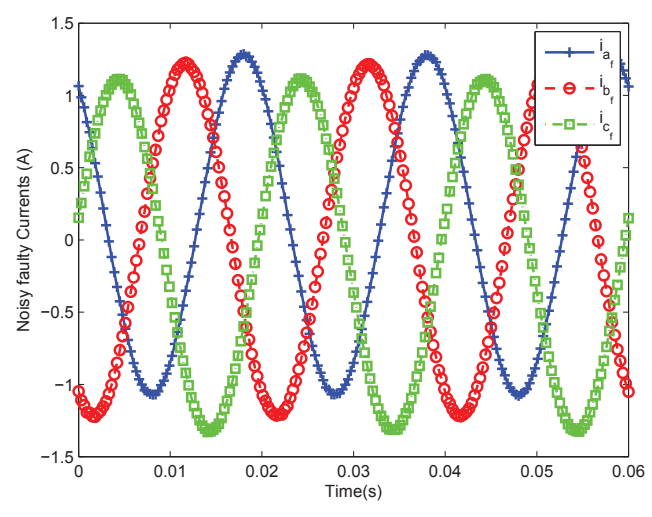

Figure 8. Faulty currents with $\mathrm{SNR}=20 \mathrm{~dB}$, Gain fault $25 \%$, Offset fault $15 \%$ and Phase shift $35 \%$

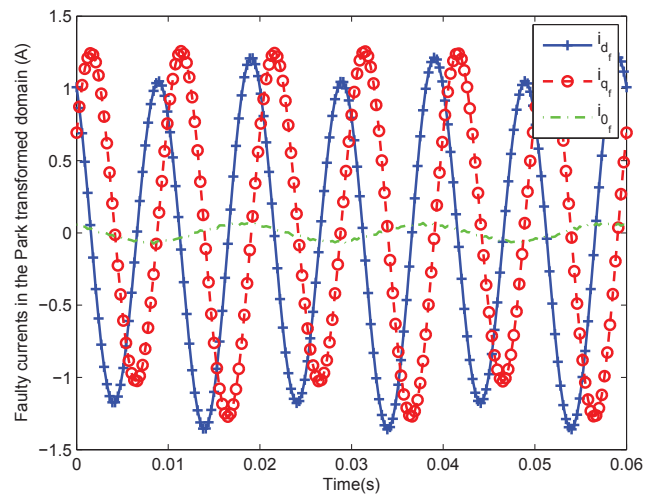

Figure 9. Faulty currents in the Park transform domain for fault conditions: Gain $25 \%$, Offset $15 \%$ and Phase shift $35 \%$

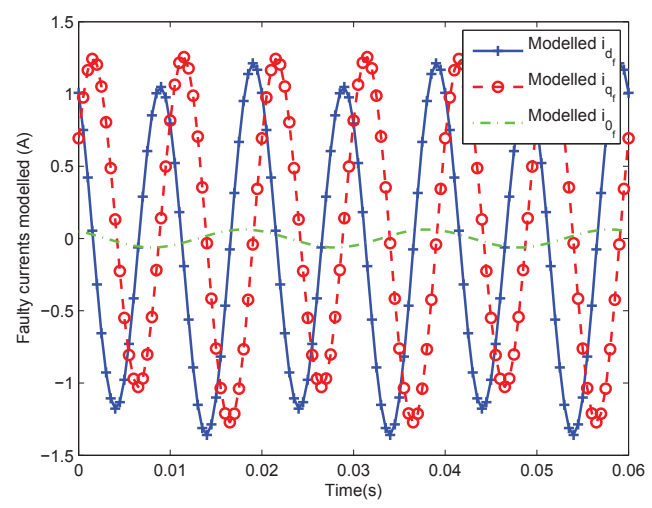

Figure 10. Model of the currents $i_{d_{f}}, i_{q_{f}}$ and $i_{0_{f}}$

modelled and simulated current. On Figure 11 the signals corresponding to $i_{d_{f}}$ are displayed. These two currents are exactly the same (same amplitude with same frequency spectrum). While computing the error we obtain a mean value equal to $1 \times 10^{-16}$. This proves that the model derived in (11) is accurate. 


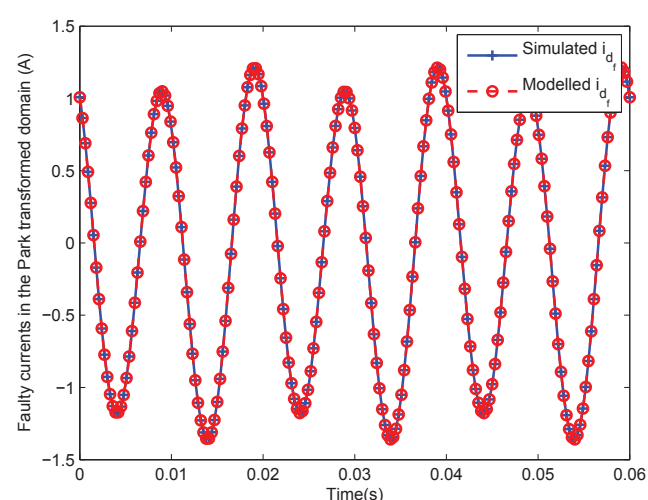

Figure 11. Faulty Park transformed current $i_{d}$ comparison between modelled and simulated signal

On Figure 12 the signals corresponding to $i_{q_{f}}$ are displayed. The 2 currents are very close (same amplitude with same frequency spectrum). The mean error value between the two currents is equal to $1.6 \times 10^{-17}$. This proves the efficiency of the model derived in (13).

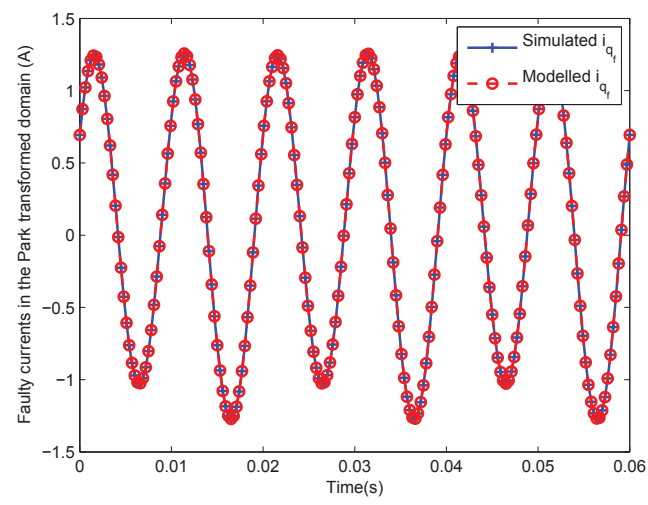

Figure 12. Faulty Park transformed current $i_{q}$ comparison between modelled and simulated signal

On Figure 13 the two signals corresponding to $i_{0_{f}}$ are displayed. They are similar even if the simulated one is widely influenced by the noise level. The mean error value between these two currents is $4.4 \times 10^{-4}$. This value is higher than those obtained for $i_{d_{f}}$, and $i_{q_{f}}$, because of their lower amplitude. The efficiency of the model derived in (14) is proved.

\section{Conclusion}

In this paper we have studied the effect of combined multiple faults on the currents feeding AC drive motors. We have proposed to consider gain faults, offset faults and phase shifting faults for the three phase currents. We have proposed to do this study in the $(\mathrm{d}, \mathrm{q})$ Park transformed domain. We propose a theoretical model for the three park currents $i_{d}$, $i_{q}$ and $i_{0}$ taking into account the fault effect. We prove the

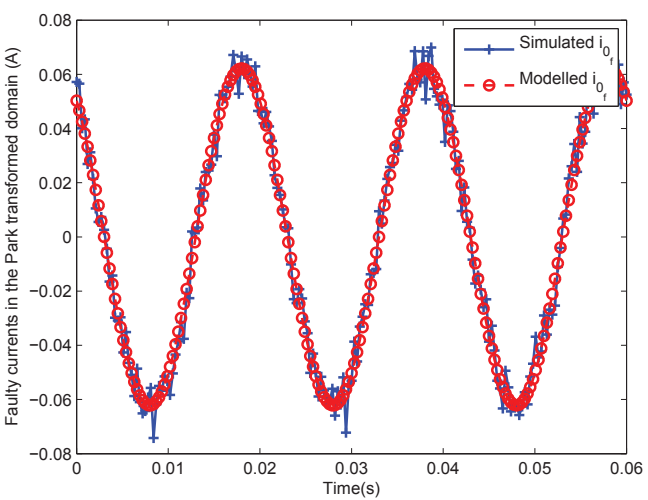

Figure 13. Faulty Park transformed current $i_{0}$ comparison between modelled and simulated signal

efficiency of the proposed model compared to the simulated signals. Such approach is useful to forecast the currents behaviors for prognosis and the evolution of the system. Moreover, while reversing these models, they could be efficiently used for estimating the faults severity characteristics for diagnosis purpose.

\section{REFERENCES}

[1] R. Isermann, Fault-Diagnosis Systems: An Introduction from Fault Detection to Fault Tolerance. Berlin Heidelberg: Springer, 2006.

[2] J. Trigeassou, Electrical Machines Diagnosis. Wiley, ISTE, 2011

[3] R. Isermann, "Supervision, fault-detection and fault diagnosis methods, an introduction," Control Eng. Practice, vol. 5, no. 5, pp. 639-652, 1997.

[4] M. Basseville and I. V. Nikiforov, Detection of Abrupt Changes-Theory and Application, ser. Prentice Hall information and system sciences series. Prentice Hall, Englewood Cliffs, NJ, 1993.

[5] J. Harmouche, C. Delpha, D. Diallo, and Y. Le-Bihan, "Statistical approach for non-destructive incipient damage detection and characterisation using kullback-leibler divergence," IEEE Transaction on Reliability, 2016, accepted.

[6] S. Nandi and H. Toliyat, "Condition monitoring and fault diagnosis of electrical motors-a review," IEEE Transactions on Energy Conversion, vol. 20, no. 4, pp. 719-729, 2005

[7] C. Delpha, D. Diallo, M. Benbouzid, and C. Marchand, "Application of classification methods in fault detection and diagnosis of inverter fed induction machine drive : A trend towards reliability," European Physical Journal of Applied Physics, vol. 43, pp. 245-251, 2008.

[8] S. Diao, D. Diallo, Z. Makni, C. Marchand, and J. Bisson, "A differential algebraic estimator for sensorless permanent-magnet synchronous machine drive," IEEE Transaction on Energy Conversion, vol. 30, no. 1, pp. 82 - 89, March 2015

[9] J. Guzinski and H. A. Abu-Rub, H.and Toliyat, "Speed sensorless ac drive with inverter output filter and fault detection using load torque signal," in 2010 IEEE International Symposium on Industrial Electronics. Bari: IEEE, July 4-7 2010, pp. 3113-3118.

[10] G. Stojicic, M. Samonig, P. Nussbaumer, G. Joksimovic, M. VaŽak, N. Peric, and T. M. Wolbank, "A method to detect missing magnetic slot wedges in ac machines without disassembling," in IECON 2011 - 37th Annual Conference on IEEE Industrial Electronics Society, Melbourne, VIC, Nov. 7-10 2011, pp. 1698-1703.

[11] J. Harmouche, C. Delpha, and D. Diallo, "Improved fault diagnosis of ball bearings based on the global spectrum of vibration signals," IEEE Transaction on Energy Conversion, vol. 30, no. 1, pp. 376 - 383, March 2015

[12] M. Tsypkin, "Induction motor condition monitoring: Vibration analysis technique - a twice line frequency component as a diagnostic tool," IEEE International Electric Machines \& Drives Conference (IEMDC), vol. 4 no. 2, pp. 117-124, 2013. 